\title{
Thresholds of control-display lag as a function of display movement rates
}

JOSEPH A. STEGER ${ }^{2}$ AND HOWARD SHERMAN, GRUMMAN AIRCRAFT ENGINEERING CORPORATION

To insure validity of space flight simulation it was necessary to provide an estimate of control-display lag below which the human operator would not detect such a lag. Using three rates of display movement and $10 \mathrm{Ss}$ it was found that $75 \%$ of the detectable lag was above $100 \mathrm{msec}$. However, rate of display movement had an orderly effect upon detection. The faster the movement rate the longer the control-display lag before detection.

During simulation of lunar landing and other space vehicle maneuvers a pictorial display is presented to the pilot which corresponds to actual flight conditions. This display changes corresponding to the attitude and speed of the vehicle. Ideally the control-display lag in the simulation should be equal to the lag encountered in actual space flight. Thus, as the vehicle is maneuvered, the pictorial display seen by the pilot changes accordingly. However, due to practical and mechanical limitations in simulation the pictorial display may lag behind pilot control changes more so than is found in actual vehicle flight. Thus the control-machine lag is greater in simulation than in actual vehicle flight conditions.

The question attended to in the present study was "What are the thresholds of control-pictorial display lag at various display movement rates?" This question is of obvious import for simulation since, if the control-display lag is not detectable, the simulation will have a closer correspondence to actual vehicle movement.

Although scientists have addressed themselves to the problems of detection of change in acceleration (Gottsdanker, Frick, \& Lickard, 1961; Gottsdanker, 1956) and control-display lag (Conklin, 1952; Garvey, Sweeney, \& Bermingham, 1958), to the best of our knowledge, no one has combined control-display lag and acceleration to determine lag detection thresholds.

Subjects. The Ss were 10 male engineers employed at Grumman Aircraft Engineering Corporation. All served on a voluntary basis and had no prior experience in tasks of this type.

Apparatus. The apparatus consisted of a pencil controller, a variable time delay switch and two oscilloscopes (Tektronix 545A). The pencil controller was designed and built at Grumman. The control arm of the controller was 6 in. long and $1 / 2$ in. in diameter, thus the Ss easily grasped the control arm.
When the control arm was pulled back toward the body a switch actuated the variable time delay on E's oscilloscope. E's oscilloscope then provided the signal for the S's oscilloscope. The signal was a vertical line $2 \mathrm{~mm}$ wide and 10 $\mathrm{cm}$ long which swept the face of the S's scope at one of three rates. The sweep rates were based on typical vehicle movement rates of $1 \mathrm{deg} / \mathrm{sec}, 10$ $\mathrm{deg} / \mathrm{sec}$, and $20 \mathrm{deg} / \mathrm{sec}$. These rates at the S's viewing distance of $31 / 2 \mathrm{ft}$ corresponded to rates across the $10 \mathrm{~cm}$ scope face of $3 \mathrm{~cm} / \mathrm{sec}, 20 \mathrm{~cm} / \mathrm{sec}$, and $40 \mathrm{~cm} / \mathrm{sec}$, respectively.

The use of two oscilloscopes provided the $E$ with a control of the delay and sweep rates which was concealed from the S's view. All experimentation was done in a quiet room free from outside illumination. The $S$ sat in an arm chair on which was mounted the pencil controller. S's arm rested on the arm support with his hand at the control arm. This was adjusted for the convenience of each $\mathbf{S}$.

Procedure. The procedure was designed to investigate under each of the three movement rates, eight control-signal delay intervals from 25 to 200 msec in steps of $25 \mathrm{msec}$ for a total of 24 experimental conditions. There were 10 repetitions per condition for a total of 240 trials under which each $S$ served. All conditions were randomly ordered throughout the 240 trials to control for possible response set and learning.

The actual procedure can best be understood from the following instructions given the $S$ after he was seated facing the oscilloscope.

"On the oscilloscope facing you, appears a line (E points to it). As you move the control stick this line will sweep across the face of the scope (E demonstrates). Please pull back the control quickly.

"We would like you to report if there is a time lag between the time you pull back the control stick and when the display sweeps across the scope. Just report yes or no depending on whether you detect a delay or not. On some trials there will be no delay and on others there will be an obvious delay. I will show you an obvious delay (E demonstrated a $200 \mathrm{msec}$ delay at $5 \mathrm{sec}$ sweep).

"The procedure will be this: I'll say O.K. and you initiate your controller, then report yes or no and permit the control to return to the starting position.

"Do you have any questions?"

After the instructions the $S$ was given one trial to familiarize himself with the procedure and then the experimental trials began. There was a $5 \mathrm{~min}$ break after 120 trials.

Results. An analysis of variance was conducted using an arcsine transformation and both the control-display lag and the rates of movement as well as their interaction produced statistically significant effects $(p \leqslant .05)$.

From the data shown in Fig. 1 it can be seen that the rate at

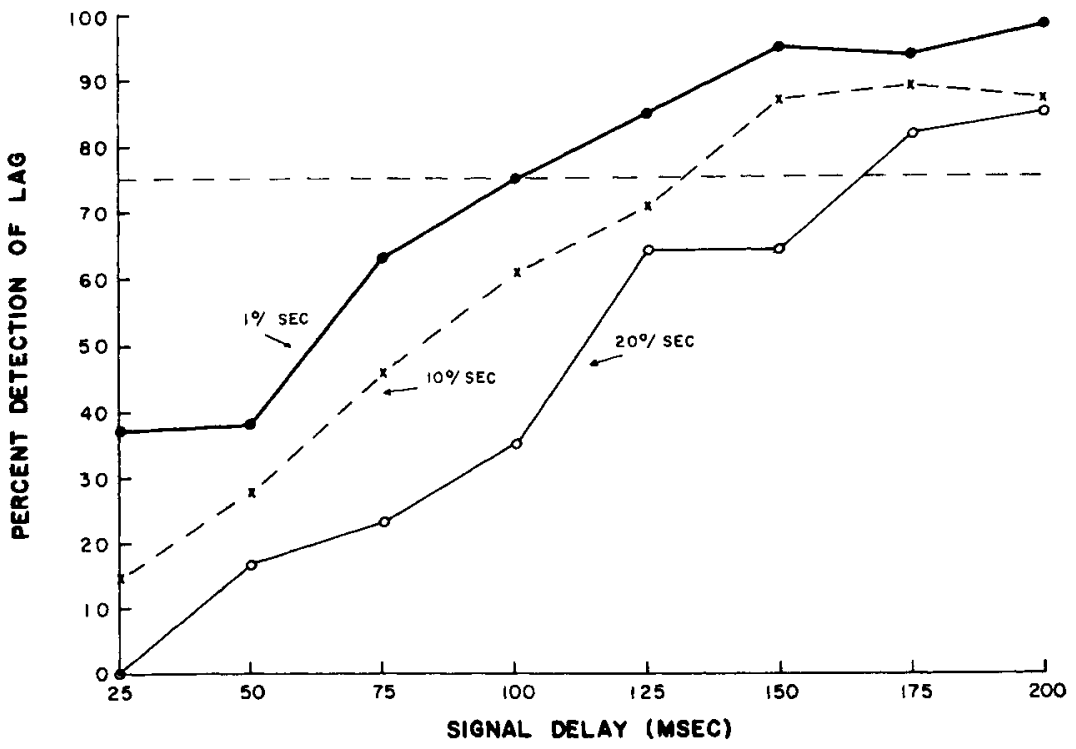

Fis. 1. Per cent detection of controldisplay lag as a function of signal delay and sweep rate. 


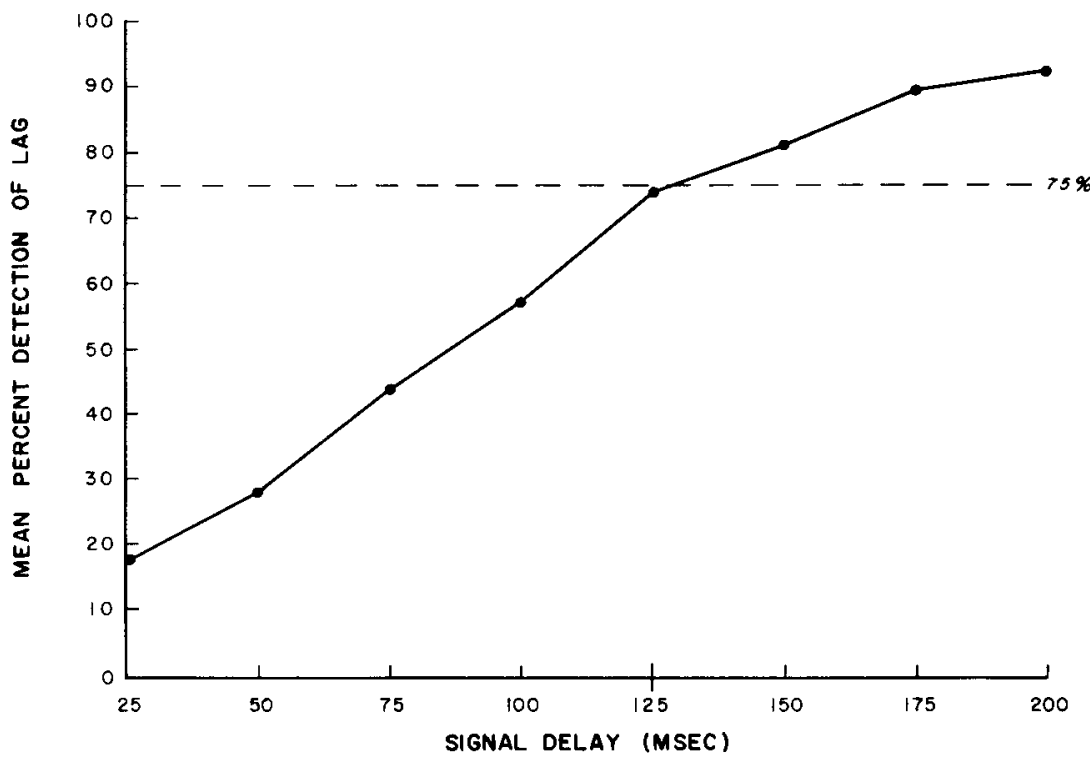

Fig. 2. Mean per cent detection of control-display lag all sweep rates combined. which the display swept the face of the scope had an obvious and orderly effect upon the detection of control-display lag. At the slower display movement rates very small control-display lags were detected. The faster $(20 \mathrm{deg} / \mathrm{sec})$ rate, however, required much larger lags before detection was reported. Thus, the $75 \%$ detection threshold for the $1 \mathrm{deg} / \mathrm{sec}$ sweep rate was $100 \mathrm{msec}$, for the 10 $\mathrm{deg} / \mathrm{sec}$ sweep rate it was $125 \mathrm{msec}$, and for the $20 \mathrm{deg} / \mathrm{sec}$ sweep rate it was between 150 and $175 \mathrm{msec}$. There is, then, approximately a $75 \mathrm{msec}$ difference between the lowest $75 \%$ threshold of lag detection $100 \mathrm{msec}$ at $1 \mathrm{deg} / \mathrm{sec}$ sweep and the highest 175 $\mathrm{msec}$ at $20 \mathrm{deg} / \mathrm{sec}$ sweep. Once the control display lag was beyond $175 \mathrm{msec}$ it was very regularly detected regardless of display movement speed.

It should be noted that the slow display sweep rate $(1 / \mathrm{sec})$ may have been confused with the actual control-display lag. That is, the slow movement of the target away from the side of the face of the scope may have been confused with a control lag and reported as a detection of lag. This may have caused the high per cent detection at the $25 \mathrm{msec}$ control-display lag interval for $1 \mathrm{deg} / \mathrm{sec}$ sweep rate.

No significance tests were conducted for Ss nor for any interaction involving Ss. The problems associated with the interpretation of such tests have been discussed elsewhere (Mentqer, 1953; McNemar, 1955). The range of the S's mean 75\% detection threshold for all rates combined was from approximately $90 \mathrm{msec}$ to $150 \mathrm{msec}$. However, eight of the ten Ss had mean $75 \%$ detection thresholds above the $100 \mathrm{msec}$ controldisplay lag.

Figure 2 shows the mean per cent detection combining all sweep rates. The logic here was that all of the rates would be encountered in display simulation so our best guess at the mean detection at the $75 \%$ threshold for all rates would be the mean of the three movement rates combined.

The $75 \%$ lag detection threshold in this case is $125 \mathrm{msec}$ as above. There appears to be a critical control-display lag detection zone between $100 \mathrm{msec}$ and $125 \mathrm{msec}$ where a mean increase in approximately $20 \%$ occurred.

Discussion. It is apparent from the findings that a control-display lag including that of normal machine lag can be detected fairly regularly above $100 \mathrm{msec}$. It would appear that any control-display lag which is to be tolerated in a simulation system should be well below this $100 \mathrm{msec}$ to ensure correspondence between simulation and actual control or flight conditions.

\section{REFERENCES}

CONKLIN, J. R. Effect of control lag on performance in a tracking task. $J$. exp. Psychol, 1957, 53, 261-268.

GARVEY, W. D., SWEENEY, J. S., \& BERMINGHAM, H. P. Differential effects of "display lags" and "control lags" on the performance of manual tracking systems. J. exp. Psychol., 1958, 56, 8-10.

GOTTSDANKER, $R$. The ability of human operators to detect acceleration of target motion. Psychol. Bull., 1956, 53, 447-478.

GOTTSDANKER, R., FRICK, J. W., \& LOCKARD, R. B. Identifying the acceleration of visual targets. Brit. J. Psychol., 1961, 52, 31-42.

McNEMAR, W. Psychological statistics. New York: Wiley, 1962.

MENTZER, L. G. Tests by the analysis of variance, WADC Technical Report, $52-53,1953$.

\section{NOTES}

1. This research was conducted at Grumman Aircraft Engineering Corporation under NASA contract NAS 9-1100.

2. Now at State University of New York at Albany, 1400 Washington Ave., Albany, N. Y. 